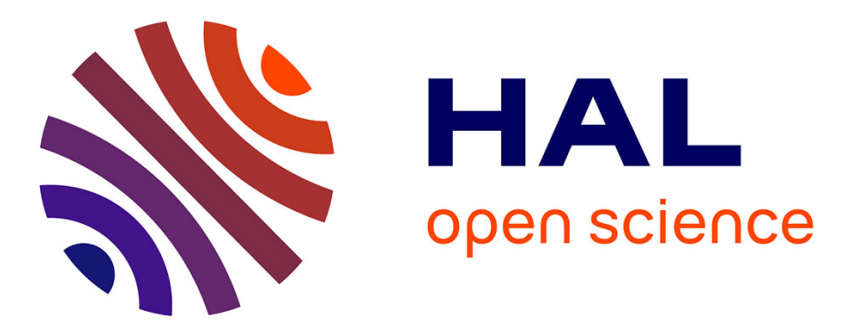

\title{
Atlantic salmon return rate increases with smolt length
}

Stephen Gregory, Anton Ibbotson, William Riley, Marie Nevoux, Rasmus Lauridsen, Ian Russell, J Robert Britton, Phillipa Gillingham, Olivia Simmons, Etienne Rivot

\section{- To cite this version:}

Stephen Gregory, Anton Ibbotson, William Riley, Marie Nevoux, Rasmus Lauridsen, et al.. Atlantic salmon return rate increases with smolt length. ICES Journal of Marine Science, 2019, 76 (6), pp.17021712. 10.1093/icesjms/fsz066 . hal-02272105

\section{HAL Id: hal-02272105}

\section{https://institut-agro-rennes-angers.hal.science/hal-02272105}

Submitted on 6 Jan 2020

HAL is a multi-disciplinary open access archive for the deposit and dissemination of scientific research documents, whether they are published or not. The documents may come from teaching and research institutions in France or abroad, or from public or private research centers.
L'archive ouverte pluridisciplinaire HAL, est destinée au dépôt et à la diffusion de documents scientifiques de niveau recherche, publiés ou non, émanant des établissements d'enseignement et de recherche français ou étrangers, des laboratoires publics ou privés. 


\title{
Atlantic salmon return rate increases with smolt length
}

\author{
Stephen D. Gregory ${ }^{1,}{ }^{*}$, Anton T. Ibbotson ${ }^{1}$, William D. Riley ${ }^{2}$, Marie Nevoux ${ }^{3,4}$, Rasmus B. \\ Lauridsen ${ }^{1}$, Ian C. Russell ${ }^{2}$, J. Robert Britton ${ }^{5}$, Phillipa K. Gillingham ${ }^{5}$, Olivia M. Simmons ${ }^{1,5}$, \\ Etienne Rivot ${ }^{3,4}$
}

\author{
${ }^{1}$ Salmon and Trout Research Centre, Game and Wildlife Conservation Trust, FBA River Laboratory, Wareham, \\ Dorset, UK \\ 2 The Centre for Environment, Fisheries and Aquaculture Science, Lowestoft, Suffolk, UK \\ ${ }^{3}$ ESE, Ecology and Ecosystems Health, INRA, Agrocampus Ouest, Rennes, France \\ 4 Management of Diadromous Fish in their Environment, AFB, INRA, Agrocampus Ouest, Université de Pau et \\ des Pays de l'Adour/E2S UPPA, Rennes, France \\ ${ }^{5}$ Centre for Conservation Ecology and Environmental Sciences, Faculty of Science and Technology, \\ Bournemouth University, Poole, Dorset, UK \\ *Corresponding author: tel: +44 1929401 882; email: sgregory@gwct.org.uk, \\ stephendavidgregory@gmail.com.
}

\begin{abstract}
Recent declines in Atlantic salmon Salmo salar populations are generally attributed to factors in their marine life-phase. Recently, however, it has been postulated that factors affecting their freshwater juvenile life-phase might be impacting their marine survival, such as the influence of body size. Whilst it has been hypothesised that larger smolts have higher marine survival rates, empirical support for this remains scant, in part due to inadequate data and ambiguous statistical analyses. Consequently, here we test the influence of smolt body size on marine return rates, a proxy for marine survival, using a 12year dataset for the River Frome, Southern England, based on passive integrated transponder (PIT) tagged fish. State space models describe the probability of smolts surviving their marine phase to return as 1 sea-winter (1SW) or multi-sea-winter (MSW) adults as a function of their length, while accounting for imperfect detection and missing data. Models predicted that larger smolts had higher return rates; the most parsimonious model included the effect of length on 1SW return rate. This prediction is concerning, as
\end{abstract}


freshwater juvenile salmon are decreasing in size on the River Frome. Thus, to maximise adult returns, restoration efforts should focus on maximising both the number and the size of emigrating smolts.

Keywords salmonid, Bayesian inference, size effect, marine survival, passive integrated transponder (PIT), probability to return as adult, juvenile, state space model

\section{Introduction}

Populations of Atlantic salmon Salmo salar have declined in abundance precipitously across their range since the 1970s (Parrish et al., 1998; Limburg and Waldman, 2009; Mills et al., 2013). The causes of their decline are multifactorial and has been attributed to a range of interacting extrinsic and intrinsic factors affecting the whole life cycle and the marine phase in particular (Friedland et al., 2000; Friedland et al., 2003; Peyronnet et al., 2007; Peyronnet, et al., 2008; Hogan and Friedland, 2010). Extrinsic factors likely include the direct effects of climate-driven food availability (e.g., Beaugrand and Reid, 2012), exposure to pesticides or pollutants (e.g., Moore et al., 2008) and fluctuating predation pressure (e.g., Riley et al., 2011). Intrinsic factors often act directly on the freshwater phase and likely affect smolt migration timing (e.g., Otero et al., 2014) and smolt body size and condition (e.g., Armstrong et al., 2018), which might be heritable (e.g., Withler et al., 1987). Although useful, the distinction between extrinsic and intrinsic factors is not unambiguous; a factor can be either extrinsic or intrinsic and interact with other factors, e.g., the effect of environmental conditions on smolt migration timing (e.g., Otero et al., 2014). To better manage and restore $S$. salar stocks, there is a need to better understand the influence of these extrinsic and intrinsic factors, and their interactive and legacy effects, on the life history traits and behaviours of fish (Clutton-Brock and Sheldon, 2010).

Marine survival of emigrating smolts is acknowledged as one of the main bottlenecks for $S$. salar population dynamic and productivity (Friedland, 1998; Friedland et al., 2000). Recent declines in $S$. salar stocks have tended to be attributed to extrinsic factors thought to affect survival at sea (e.g., Beaugrand and Reid, 2012; Olmos et al., 2019). However, there is increasing speculation that effects carried over from their freshwater phase are also 
important determinants of $S$. salar marine return rates (Russell et al., 2012). A potenitally rewarding strategy to improve management of $S$. salar populations might be to promote the quality of emigrating smolts to maximize their marine survival (Russell et al., 2012). However, the relationships between smolts characteristics and their marine survival is not clear.

It has been long speculated that smolt mortality is inversely related to their body size, i.e., the inverse-weight hypothesis (Ricker, 1976). Indeed, many studies have provided some empirical evidence of this 'bigger is better' paradigm (sensu Sogard, 1997). For instance, Koenings et al. (1993) suggested a positive but non-linear influence of smolt length on marine return rates in 12 populations, but that was exacerbated by latitudinal variation. Although this paradigm is generally accepted due to its intuitive nature (e.g., larger fish avoiding gape-limited predators), its universality is questionable. For example, Jonsson $e t$ al. (2017) showed that medium-sized smolts had the highest marine return rates in the River Imsa, Norway, although the relatively low return rate of larger smolts could not be disentangled from the influence of their emigration timing. Ewing and Ewing (2002) reported that larger fish had lower marine return rates than smaller fish, i.e., that the effect of length on return rate was negative, perhaps because they were precocious male juveniles that invest more energy in reproduction than immature males.

A recent review of literature that empirically tested the 'bigger is better' paradigm for $S$. salar concluded that the evidence was equivocal, due in part to inadequate data or unsupported experimental and statistical assumptions (Gregory et al., 2018). For example, several studies related mean length to adult return rate through time or space, which assumes that any effect of length can be captured at a population-level, and individual-level effects can be disregarded as noise (e.g., Henderson and Cass, 1991; Dempson et al., 2003). Other studies have used individual lengths back-calculated from scales of returning adults, and then suffered from unquantified uncertainty due to measurement error and choice of back-calculation model and are potentially biased due to the use of only those individuals that were seen returning (e.g., Holtby et al., 1990; Henderson and Cass, 1991). Several studies have overlooked or omitted consideration of the sampling or observation process, i.e., sampling or detection was assumed to be $100 \%$ efficient (e.g., Dieperink et al., 2002; 
Newton et al., 2016). This can be considered unlikely given that detection is usually imperfect, with an unknown proportion of the adults returning undetected (but see Armstrong et al. [2018] for an exception). Neglecting uncertainty due to sampling or observation processes can result in a biased representation of the process of interest (Kéry and Schmidt, 2008). The recognition that the sampling or observation process needs to be accounted for when investigating effects of individual heterogeneity has motivated the development of capture-mark-recapture (CMR) models, fitted in a state-space modeling (SSM) framework. These models separate the observation from the ecological process (Gimenez et al., 2007; Gimenez et al., 2018), and so have particular application for testing the 'bigger is better' paradigm in anadromous salmonids (Gregory et al., 2018).

In this study, we developed a multi-state CMR state-space model (Gimenez et al., 2007; Gregory et al., 2018; Gimenez et al., 2018) to test the effect of smolt length on their subsequent marine return rate, while considering random effects of year and uncertainty in the observation process. The model is designed to separate the effect of smolt length on their subsequent return rate from other effects: (1) the time individuals spend at sea (here one or more winters), which is thought to be related to marine mortality rates, i.e., individuals spending more time at sea suffer higher mortality at sea; (2) variation in marine return rate due to other (explanatory) variables, such as years; (3) imperfect detection of returning adults due to inefficiency in monitoring devices; and (4) data loss due to failure of monitoring devices.

\section{Methods}

\section{Smolt and adult monitoring on the River Frome, Southern England}

Individual $S$. salar smolts that emigrate from and return to the River Frome have been monitored using passive integrated transponder (PIT) telemetry since 2006. The River Frome is a lowland chalk stream that rises at Evershot (Lat. 5050'24“N; Long. 2036'12”W) before traveling through highly braided but largely non-impounded channels some $70 \mathrm{~km}$ to the tidal limit at Wareham (Lat. 50॰40’38“N; Long. 207'3”W). The River Frome salmon population declined markedly in 1989-90, together with other populations around the 
Atlantic basin (Olmos et al., 2019), and has been declining or stable since. Each autumn (late-August to mid-September), approximately 10,000 individual parr (non-migratory, freshwater juvenile salmon) were captured and marked with a PIT tag inserted into the coelomic cavity under anaesthesia (2-phenoxy-ethanol) and returned to the river at their site of capture (see additional information on the protocol and other biometric measures in Ibbotson et al. [2013]). In the following spring (late-March to mid-May), >95\% of River Frome parr smoltify and migrate to sea (Ibbotson et al., 2013). These smolts are sampled on their sea-ward migration by capturing individuals in a rotary screw trap (RST; Figure 1, Table 1). The RST is positioned downstream of a fluvarium in an experimental stream, which is separated from the main river by a bioacoustic fence that deflects migrating smolts into the experimental stream. Together, the bioacoustic fence and fluvarium allow us to maximise the probability of encountering and capturing a random sample of migrating salmon smolts. Until spring 2013, the RST was operated for 24 hours every day throughout the period of smolt migration; after then it was operated pragmatically to sample throughout the duration of the smolt migration period and the diurnal migration pattern, which amounted to $>12$ hours for $>35$ days (of $\approx 50$ days). During operation, the RST was emptied every 30 minutes and captured smolts were removed, sedated (2phenoxy-ethanol) and checked for a PIT tag. Tagged individuals were measured (fork length, nearest $\mathrm{mm}$ ), weighed (g), and between 2006 and 2012 (inclusive) marked with an additional Coded Wire Tag (Riley et al., 2018). Untagged individuals were assigned a $1 \mathrm{~cm}$ length class. All captured smolts were returned to the river 50m downstream of the RST within 1 hour of their capture.

Typically, River Frome salmon remain at sea for between 1 and 2 years (although a few individuals stay $3+$ years) before returning to the river to spawn. The returning adults are detected on two PIT antenna arrays that operate continuously (Figure 1). The first array is located $10 \mathrm{~m}$ upstream of a gauging weir and was installed in 2006. The second array is located approximately $3.5 \mathrm{~km}$ upstream of the gauging weir and was installed across several fish passage structures in 2011, meaning that it was not operational for the first 5 years of monitoring. 


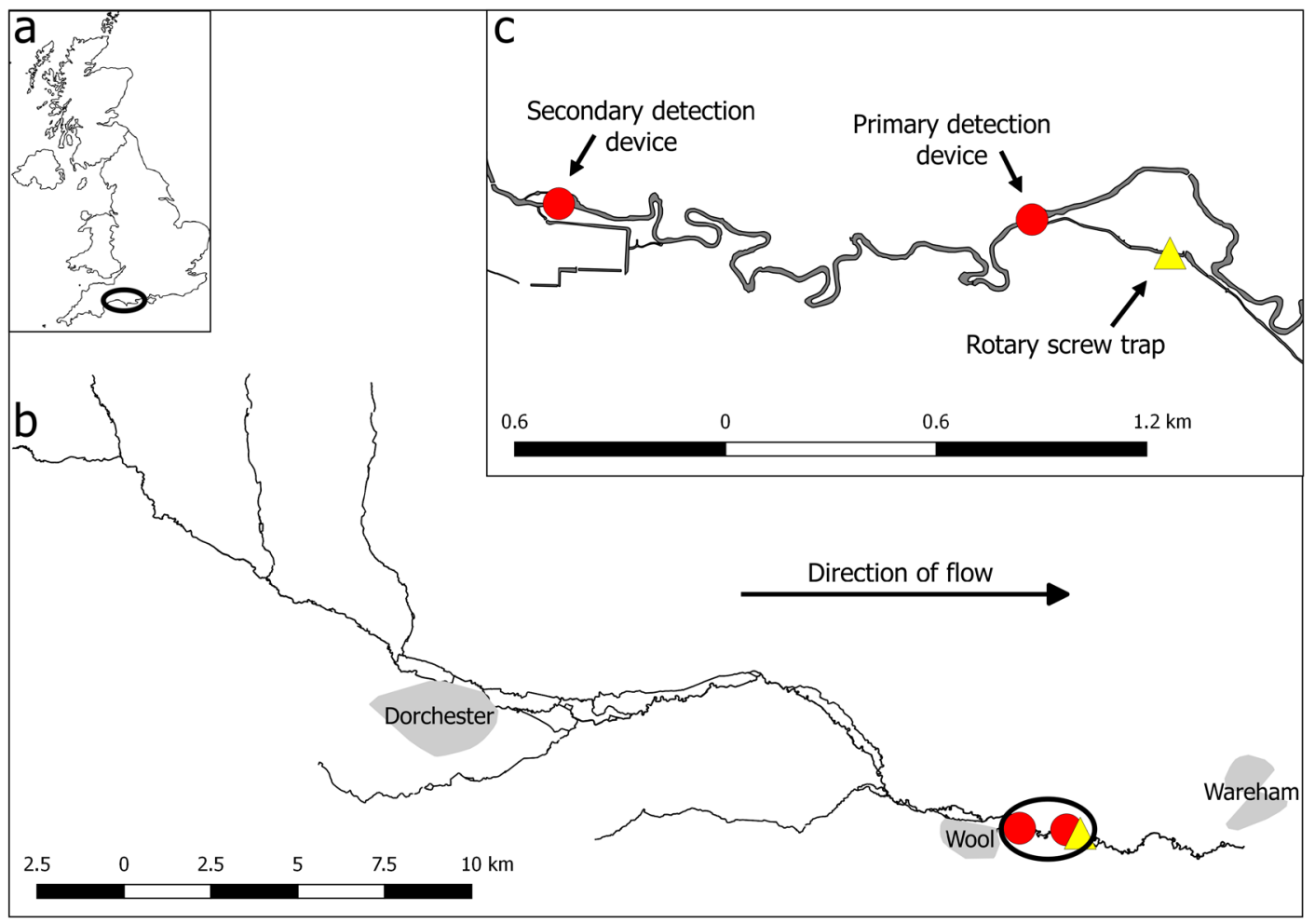

Figure 1. A map showing (a) the location of the River Frome in the UK, and the locations of the adult detection devices (red dots) and the rotary screw trap (yellow triangle) (b) in the catchment and (c) on the river.

We only considered smolts that were captured and measured in the RST. In addition, we only considered age 1 smolts in our analysis, i.e., those that emerged from eggs in the previous spring. This was because numbers of older smolts were considered too few to allow accurate estimation (Baglinière and Maisse, 1985). Smolt ages were determined from visual examination of length-frequency histograms of their fork length measured in the autumn that they were tagged as parr (Figure S1); parr exceeding $120 \mathrm{~mm}$ were considered to be age $1+$ and were removed from the analysis.

The final sample sizes analysed was 3688 and broken down by year in Table 1. Only 86 $(2.33 \%)$ of the 3688 smolts were observed returning as 1 SW or MSW adults. The number of PIT-tagged and measured smolts leaving the Frome varied annually between 224 and 628 , as did the percent of those observed returning that varied between 0.25 and 5.36 (Table 1). 
Table 1 Numbers of River Frome PIT-tagged and measured smolts released in each year that were observed returning as $1 S W$ and MSW adults or were unobserved. Unobserved adults might have died or survived but not been detected.

\begin{tabular}{lrrrr} 
Smolt cohort & Observed 1 SW & Observed MSW & Unobserved adults & Sum \\
\hline 2006 & 5 & 4 & 309 & 318 \\
2007 & 5 & 3 & 620 & 628 \\
2008 & 1 & 0 & 392 & 393 \\
2009 & 5 & 6 & 426 & 437 \\
2010 & 7 & 5 & 345 & 357 \\
2011 & 2 & 2 & 222 & 226 \\
2012 & 2 & 2 & 220 & 224 \\
2013 & 2 & 2 & 332 & 336 \\
2014 & 5 & 5 & 298 & 308 \\
2015 & 11 & 1 & 212 & 224 \\
2016 & 11 & 0 & 226 & 237 \\
Sum & 56 & 30 & 3602 & 3688
\end{tabular}

\section{Model}

The CMR model is built in a Bayesian state-space modelling (SSM) framework that distinguishes the unknown latent process (return rates affected by smolt length and annual variations) from the observation process (imperfect detection of returning adults) (Figure 2). 


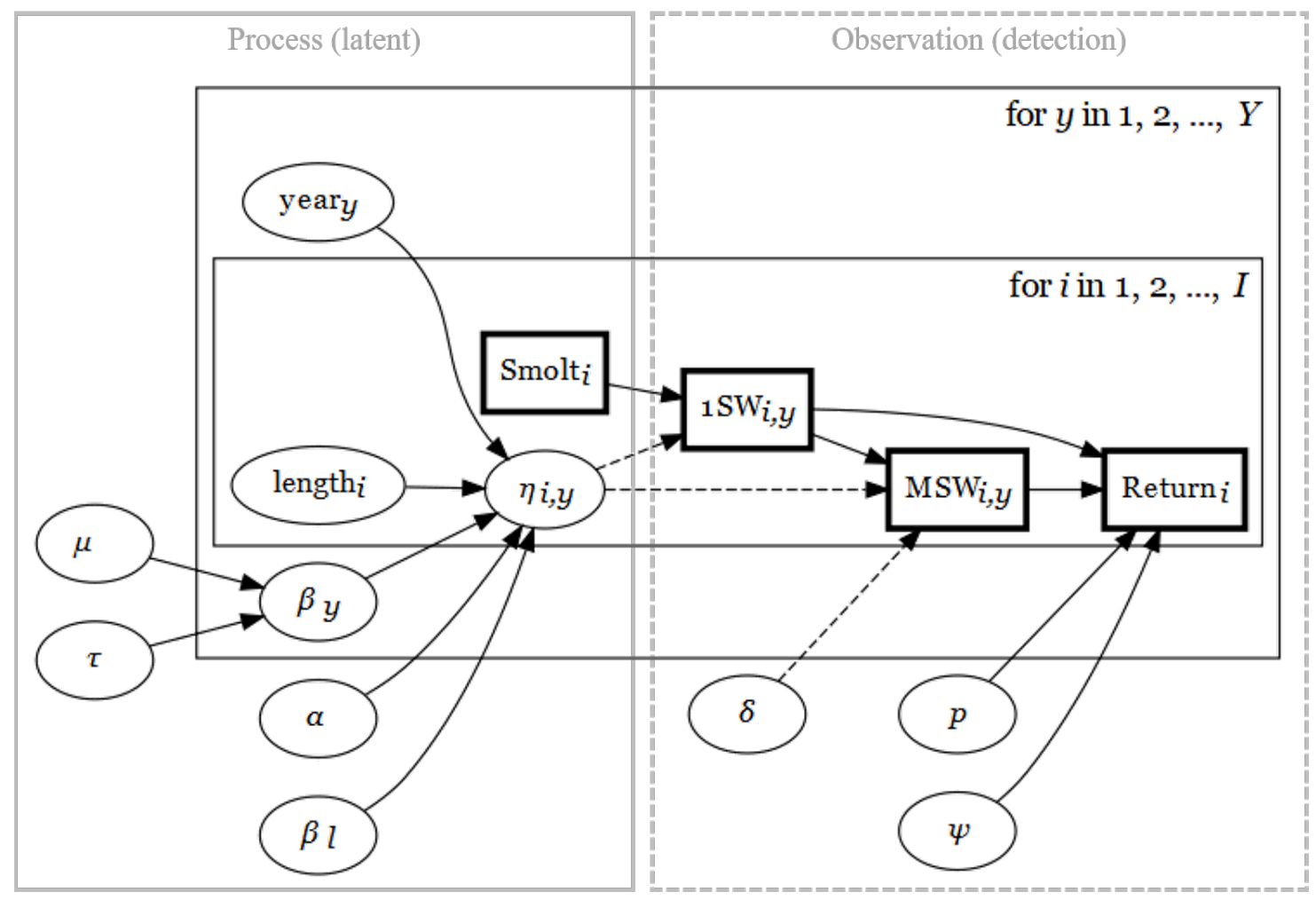

Figure 2. A directed acyclic graph showing the relationships between the parameters estimated in the multi-state capture-mark-recapture state-space model. Parameter are in ovals and are defined in the text. Data are in rectangles. Arrows represent directional relationships between parameters and data. Dashed arrows are relationships on the logit scale. Parameters and data are set within plates that represent indexes of year (y) and individual (i), where $Y$ and I are the total number of years and individuals, respectively. Grey rectangles indicate separation of the process and observation (or latent and detection) parts of the model.

The core assumptions of the model are:

(1) smolt length affects return rates after one year at sea (hereafter 1 sea-winter [1SW]), and MSW return rate is equal to the 1SW return rate penalized by a constant term (constant between years and individuals) to capture the additional mortality due to an additional time spent at sea. Imposing a strong relationship between 1SW and MSW returns rates is needed because the sample size of observed adult returns was deemed too low to treat them separately. However, this hypothesis is consistent with the 
available literature that suggests the highest mortality occurs initially after smolts leave freshwater, i.e., when they are at their smallest, rather than in their second or more year at sea (Friedland, 1998; Friedland et al., 2000). Moreover, it has been postulated that marine mortality is higher and more variable for post-smolts in their first year at sea compared to larger adult salmon in their second or later year at sea (Potter et al., 1998);

(2) the effect of smolt length on their 1SW return rate was constant between years and individuals;

(3) random terms account for additional random variations between years;

(4) all smolt lengths were measured without error, were observed at their point of release, and suffered no mortality between the point of release and their arrival at the marine environment;

(5) the primary adult detection device efficiency was unknown but constant between years and individuals;

(6) adult survival between the primary and secondary adult detection devices was unknown but constant between years and individuals; and

(7) the usual CMR assumptions, specifically that marks are not lost or harmful, individuals are independent and a random sample, and that individuals do not immigrate or emigrate from the population (Cooch and White, 2001).

The marine return rate of smolt $i$ with length Length $_{i}$ in its first year $y$ at sea, $\varphi_{i, y}^{1 s w}$, is modelled on the logit scale as a linear function of length with additional random effect of years:

$$
\begin{aligned}
& \operatorname{logit}\left(\varphi_{i, y}^{1 s w}\right)=\eta_{i, y} \\
& \eta_{i, y}=\alpha+\beta 0_{y}+\beta 1 \times \text { Length }_{i} \\
& \alpha \sim \operatorname{Normal}(\mu=0, \sigma=1 / 0.001) \\
& \beta 0_{y} \sim \operatorname{Normal}(\mu=0, \sigma=\tau) \\
& \tau \sim \operatorname{Gamma}(r=0.001, \lambda=0.001) \\
& \beta 1 \sim \operatorname{Student}-t(\mu=0, \tau=1, k=2.5)
\end{aligned}
$$


where $\beta 1$ is the length effect on return rate and $\beta 0$ is a random effect of year $y$. Note that $\tau$ is a measure of precision, related to standard deviation of the random terms $\sigma \sim \tau^{-0.5}$. All parameters were given weakly informative priors: $\alpha$ was given a Normal prior with mean 0 and large variance 1/0.001; annual deviations $\beta 0_{y}$ were given a mean 0 and common variance $\sigma$, which was given a large inverse-Gamma variance $\tau \sim \operatorname{Gamma}(0.001,0.001)^{-0.5}$. The length effect $\beta 1$ was given a Student $-t$ distribution with 1 degree of freedom, location parameter 0 and large variance.

The marine return rate of smolt $i$ as a MSW fish, denoted $\varphi_{i, y}^{m s w}$, is directly calculated from $\eta_{i, y}$ by adding a additional mortality term $\delta$ to account for one (or more) additional year spent at sea:

$$
\operatorname{logit}\left(\varphi_{i, y}^{m s w}\right)=\eta_{i, y}+\delta
$$

The state process was characterized by the transition matrix:

\begin{tabular}{lrrrr} 
& $\begin{array}{r}\text { returns as } \\
\text { smolt }\end{array}$ & $\begin{array}{r}\text { returns as } \\
\text { 1sw spawner }\end{array}$ & $\begin{array}{r}\text { returns as } \\
\text { msw spawner }\end{array}$ & dies \\
\hline smolt & 0 & $\varphi_{i, y}^{1 s w}$ & $\varphi_{i, y}^{m s w}$ & $1-\left(\varphi_{i, y}^{1 s w}+\varphi_{i, y}^{m s w}\right)$ \\
1sw & 0 & $\psi$ & 0 & $(1-\psi)$ \\
msw & 0 & 0 & $\psi$ & $(1-\psi)$ \\
dead & 0 & 0 & 0 & 1
\end{tabular}

where $\psi$ is the probability that an adult detected on the first adult detection device transitions to the second adult detection device, considered constant between individuals $i$ and year $y$, and was given a Uniform prior between 0 and 1. Note that dead individuals, i.e., those estimated to have not survived, can no longer change state and remain dead with probability 1 . The parameter $\delta$ was given a Student- $t$ distribution with 1 degree of freedom, location parameter 0 and large variance, and $\psi$ was given a Uniform prior between 0 and 1 .

Given the transitions probabilities between different states, the transition is stochastic. The transition of individual $i$ in year $y$ between state $z_{i, y, o}$ (i.e., a smolt) to state $z_{i, y, o+1}$, (i.e., a 1SW or MSW returning adult) is modelled as: 


$$
z_{i, y, o+1} \mid z_{i, y, o} \sim \operatorname{Categorical}\left(z_{i, y, o} \theta_{i}\right)
$$

where $\theta_{i}$ is the transition matrix for individual $i, \theta_{i, k}$ is a $K$-simplex for $k \in 1, \ldots, K$.

The observation process (detection) was characterised by the following transition matrix

\begin{tabular}{lrrrr} 
& seen as smolt & seen as 1sw & seen as msw & not seen \\
\hline smolt & 0 & 0 & 0 & 1 \\
1sw & 0 & $p$ & 0 & $(1-p)$ \\
msw & 0 & 0 & $p$ & $(1-p)$ \\
dead & 0 & 0 & 0 & 1
\end{tabular}

where $p$ is the efficiency of the primary adult detection device (hereafter detection efficiency), which can be thought of as the probability that the device will detect an adult (i.e., either $1 \mathrm{SW}$ or MSW). Note that the device cannot detect a smolt until it has returned as an adult and so smolt are not seen with probability 1. Note also that dead individuals, i.e., those estimated to have not survived, cannot be seen. Parameter $p$ was given a Uniform prior between 0 and 1, i.e., Uniform $(0,1)$, even though it was expected to be estimated high (Baker et al., 2017).

The likelihood of the model is specified by treating the capture history of individual $i$ in year $y$ as a sequence of $O$ observations $u_{i, y, o}$ conditioned on a sequence of the latent categorical state variables $z_{i, y, o} \in 1, \ldots, K$. The probability of observation $u_{i, y, o}$ in state $z_{i, y, o}$ at occasion $o$ is:

$$
u_{i, y, o} \mid z_{i, y, o} \sim \operatorname{Bernoulli}\left(z_{i, y, o} p\right)
$$

Assuming all individuals are first captured as smolts and are observed, i.e., $z_{i, y, 1}=1$ and $u_{i, y, 1}=1$, then the likelihood component for individual $i$ in year $y$ with capture history $u_{i, y, 1}, \ldots, u_{i, y, o}$ can then be calculated as the likelihood of observing the fish at all occasions, $u$, conditioned by the true state of the fish, $z$, integrated over all possible states of the fish (i.e., the integral over all possible $z$ ): 


$$
\int_{z_{i, y, 1}} \ldots \int_{z_{i, y, O}}\left[z_{i, y, 1}\right]\left\{\prod_{o=2}^{O}\left[u_{i, y, o} \mid z_{i, y, o}\right]\left[z_{i, y, o} \mid z_{i, y, o-1}\right]\right\} d z_{i, y, 1}, \ldots, d z_{i, y, O}
$$

where [.] denotes a probability density function.

\section{Parameter estimation}

Parameter values were estimated by MCMC using the JAGS sampler (http://mcmcjags.sourceforge.net/) run using R (http:/ /www.r-project.org/) package rjags (Plummer, 2003). Where data were missing, i.e., observations on the second adult detection device between 2006 and 2011, the log likelihood was estimated using only the state matrix by conditioning the observation matrix on a binary variable indicating where data were missing. MCMC chains run for 150,000 iterations, the first 50,000 of which were discarded as the burnin period, and parameter values at every 100th iteration were saved for inferences to limit autocorrelation in the MCMC samples. Three parallel MCMC chains were run for each analysis and all parameter estimates are presented with their 95\% Bayesian credibility intervals. Convergence was assessed by visual examination of MCMC trace plots and the Gelman-Rubin statistic (Brooks and Gelman, 1998), and were considered stable if the chains were mixing and non-convergent, i.e., $\mathrm{R}$ ratio of the Gelman-Rubin test $<1.05$ for all parameters.

\section{Model selection}

We test the effect of length on smolt marine-return rates by fitting and comparing an $a$ priori defined candidate model set. We compared three models using approximate leaveone-out cross-validation (LOO) procedure in R package loo (Vehtari et al., 2017): a "Null" model with no annual deviations or length effect, a "Year" model with annual deviations but no length effect, and a "Length" model with both annual deviations and a length effect. The approximate LOO is estimated as the model's expected log predictive density weighted by Pareto-smoothed importance sampling, which has been shown to be more robust in the finite case with weak priors or influential observations (Vehtari et al., 2017). It favours a balance between model performance and model complexity, guarding against overfitting, 
and the model with the lowest LOOIC is preferred. For more details, see Vehtari et al. (2017).

\section{Simulations}

To reassure that our findings were likely due to a real effect of length on smolt return rates, we simulated data from the "Length" model with known parameters, and used those simulated data to fit the model to examine its ability to recover the data generating parameters (e.g., Kéry and Schaub, 2012). To assess the model estimation performance under different length effect scenarios, we simulated data from the "Length" model using a weak $(\beta 1=0.15)$, moderate $(\beta 1=0.65)$ and strong $(\beta 1=1.15)$ effect of length on smolt 1SW marine return. The "moderate" effect of length was set to be close to the (rounded)

estimate from the observed data, as were the other parameters (e.g., $\varphi^{1 s w}, \varphi^{m s w}$, etc.). The simulated had a similar sample size per year as the River Frome data, i.e., 200 - 600, and were simulated for 11 years, with the first 5 years missing observations on the secondary adult detection device. The resulting parameter estimates were plotted together with their uncertainties and the simulated data generating values.

\section{Results}

\section{Simulations}

Results of the simulations approach indicate that the estimation method provided reliable estimates of all model parameters even when the length effect was weak. Our modelestimated parameters compared well with the actual data generating parameters (Figure 3) and the actual generating parameter values were all within the 95\% Bayesian credibility intervals of the model estimates (Table 2). No convergence issues were detected as all chains mixed well around the generating parameter values and all Gelman-Rubin $\mathrm{R}$ statistics were $<1.05$ (Figure S2).

Table 2 Summary estimated parameter values compared to actual generating values for the "Length" model fitted to data simulated under a "weak", "moderate" and "strong" length 
effect on smolt marine return rates and realistic detection scenarios. Parameter estimates are medians with 95\% Bayesian credibility intervals.

\begin{tabular}{lrrr} 
Treatment & Parameter & Estimate & Actual \\
\hline weak & $\varphi^{1 s w}$ & $0.024(0.012-0.042)$ & 0.02 \\
weak & $\varphi^{m s w}$ & $0.01(0.005-0.019)$ & 0.01 \\
weak & $\psi$ & $0.819(0.616-0.983)$ & 0.75 \\
weak & $p$ & $0.622(0.466-0.758)$ & 0.70 \\
weak & $\beta 1$ & $0.28(-0.081-0.649)$ & 0.15 \\
moderate & $\varphi^{1 s w}$ & $0.017(0.007-0.034)$ & 0.02 \\
moderate & $\varphi^{m s w}$ & $0.009(0.004-0.018)$ & 0.01 \\
moderate & $\psi$ & $0.925(0.782-0.997)$ & 0.75 \\
moderate & $p$ & $0.749(0.616-0.855)$ & 0.70 \\
moderate & $\beta 1$ & $0.638(0.261-1.001)$ & 0.65 \\
strong & $\varphi^{1 s w}$ & $0.018(0.01-0.031)$ & 0.02 \\
strong & $\varphi^{m s w}$ & $0.01(0.005-0.018)$ & 0.01 \\
strong & $\psi$ & $0.867(0.696-0.989)$ & 0.75 \\
strong & $p$ & $0.757(0.628-0.869)$ & 0.70 \\
strong & $\beta 1$ & $1.07(0.706-1.437)$ & 1.15
\end{tabular}




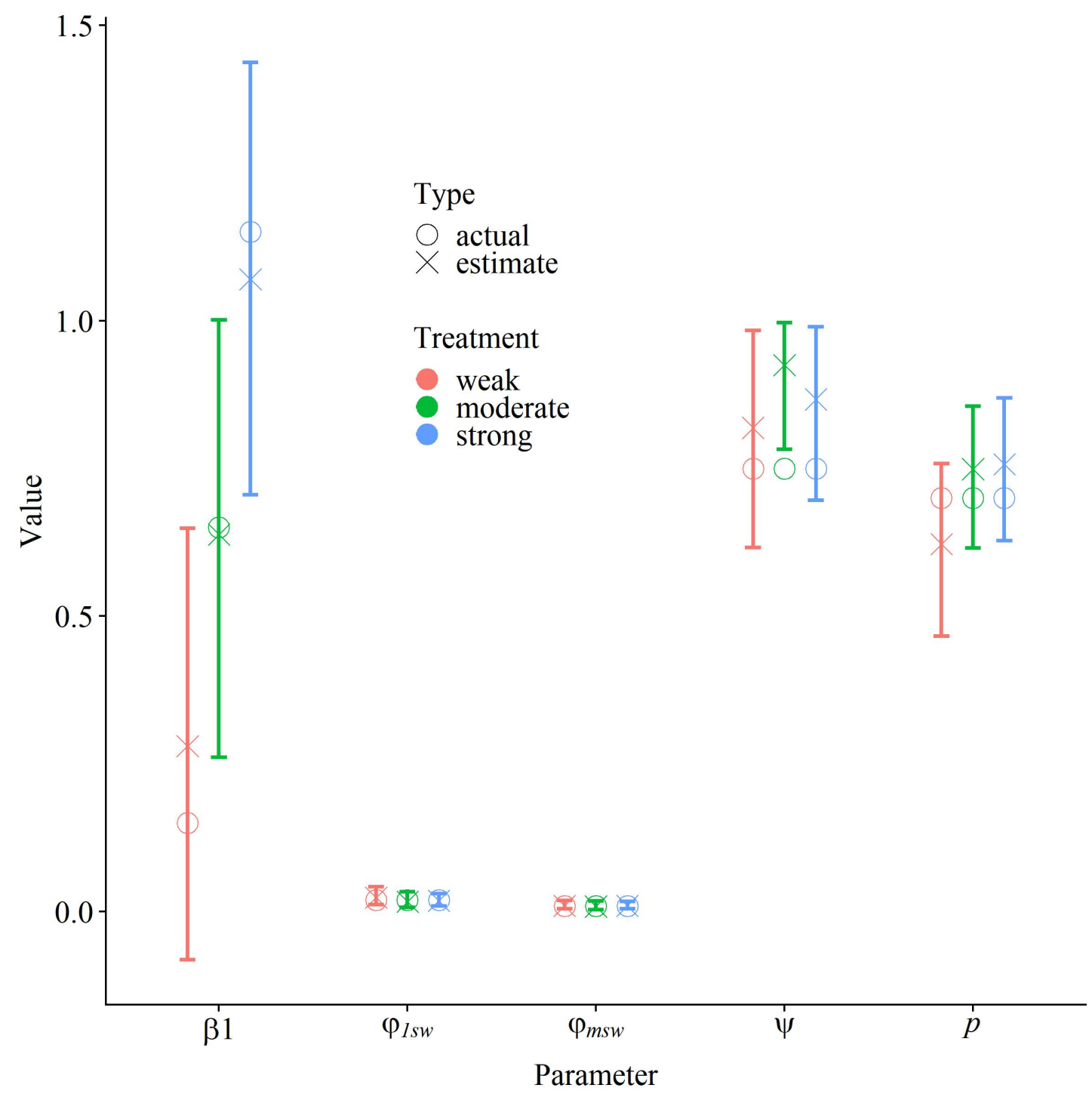

Figure 3 A plot showing the accuracy of Actual simulated data-generating parameter values compared to the values and their Estimated values when estimated by the "Length" model for a "weak", "moderate" and "strong" effect of length on smolt marine return rate. Points are medians and error bars represent the 95\% Bayesian credibility intervals.

\section{River Frome smolt return rates}

As for the simulated data, no convergence issues were detected as all chains mixed well, all Gelman-Rubin R statistics were $<1.05$, and the posterior densities were unimodal and different from the priors (Figures S3 and S4), indicating that the data provide enough information to estimate all parameters. 
The "Length" model was preferred over the "Year" model that omitted the length effect, and both over the "Null" model that omitted both the length effect and the annual deviations (Table 3).

The estimated length effect was positive and its $95 \%$ credible intervals did not intercept zero (Table 4). Over all the years analysed, the effect of smolt length was to increase their subsequent 1SW return rate from approx. 0.951\% (25-75\% quantiles: $0.95-0.958$ ) for a $120 \mathrm{~mm}$ smolt to $\approx 3.419 \%$ (25-75\% quantiles: $2.56-4.539$ ) for a $160 \mathrm{~mm}$ smolt (Figure 4 ; Figure S5). According to the "Length" model, 1SW return rate was lowest for the 2008 smolt cohort and highest for the 2015 smolt cohort (Figure 6).

We note that parr caught in the RST as spring smolts were longer in autumn than parr that were not (Figure S6). However, we chose not to speculate about whether any length effect was apparent in parr the previous autumn because we do not yet know if over-winter survival is size selective.

Table 3 Table comparing the "Length", "Year" and "Null" models using an approximate leaveone-out (LOO) predictive performance measure (expected log pointwise predictive density [ELPD]) presented as an Information Criterion statistic on the deviance scale (LOO information criterion [LOOIC]). Also given are the effective number of parameters (np) and the difference in LOOIC between the "Length" and other models (Slooic).

\begin{tabular}{lrrrr} 
& ELPD & np & LOOIC & looic \\
\hline Null model & -502.349 & 3.819 & 1004.697 & 15.50 \\
Year model & -498.32 & 10.53 & 996.65 & 7.42 \\
Length model & -494.62 & 10.92 & 989.23 & 0.00
\end{tabular}

Table 4 Parameter estimates for the River Frome data set. Parameter estimates are medians with 95\% Bayesian credible intervals.

\begin{tabular}{lrrl} 
Parameter & Null model & Year model & Length model \\
\hline$\varphi^{1 s w}$ & $0.02(0.014-0.028)$ & $0.019(0.011-0.029)$ & $0.018(0.011-0.027)$
\end{tabular}




$$
\begin{array}{lrll}
\varphi^{m s w} & 0.01(0.007-0.016) & 0.01(0.006-0.016) & 0.009(0.005-0.015) \\
\psi & 0.749(0.534-0.963) & 0.731(0.526-0.95) & 0.738(0.529-0.956) \\
p & 0.692(0.518-0.836) & 0.71(0.532-0.852) & 0.704(0.528-0.843) \\
\beta 1 & & & 0.695(0.255-1.135)
\end{array}
$$

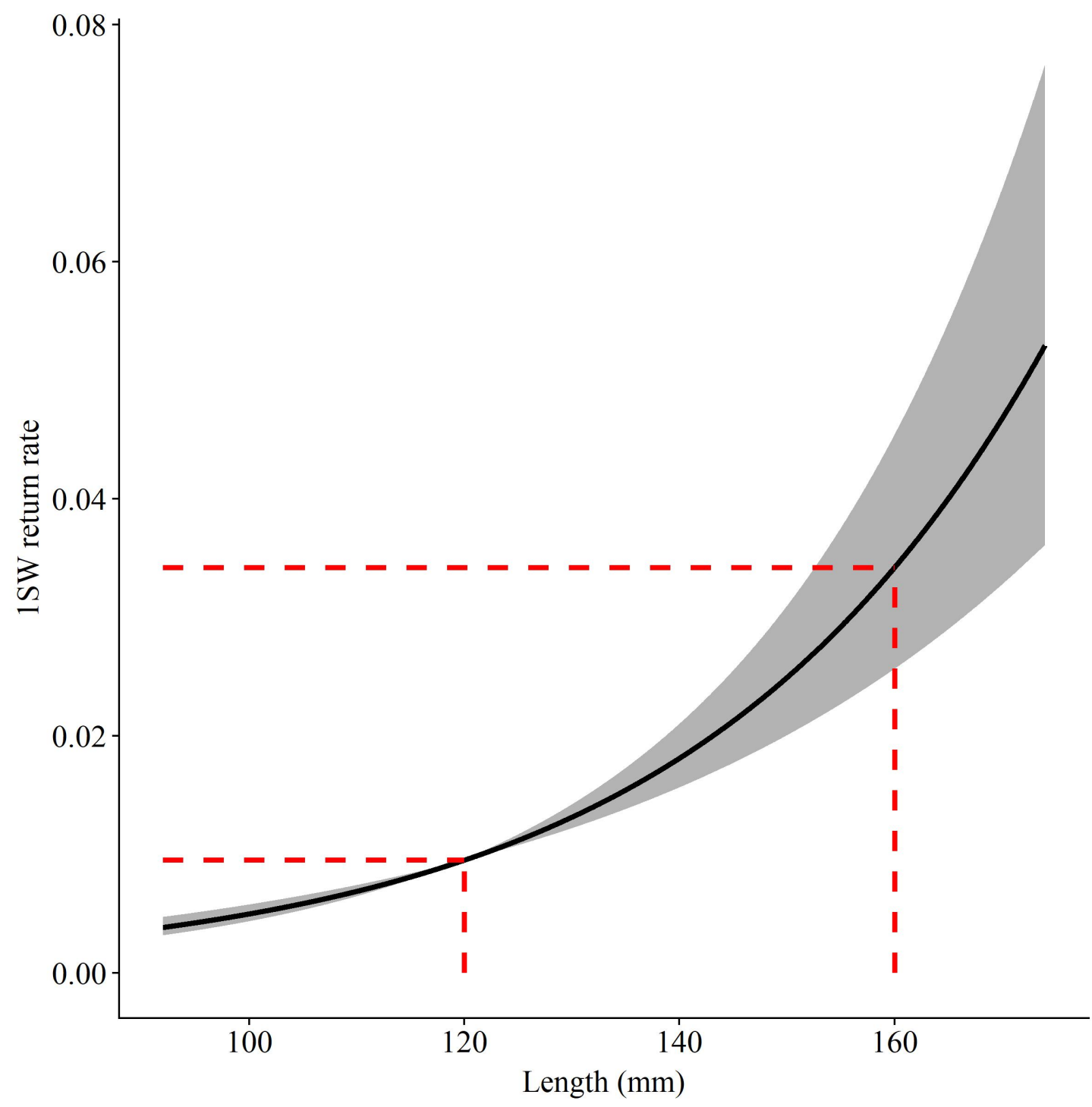

Figure 4 Estimated 1SW marine return rate as a function of fork length of individual smolt emigrating from the River Frome, Dorset, UK. Black solid line is the estimated effect and grey bands delimit the estimated 25 to 75\% Bayesian credibility interval band around that effect (approximate standard errors). 


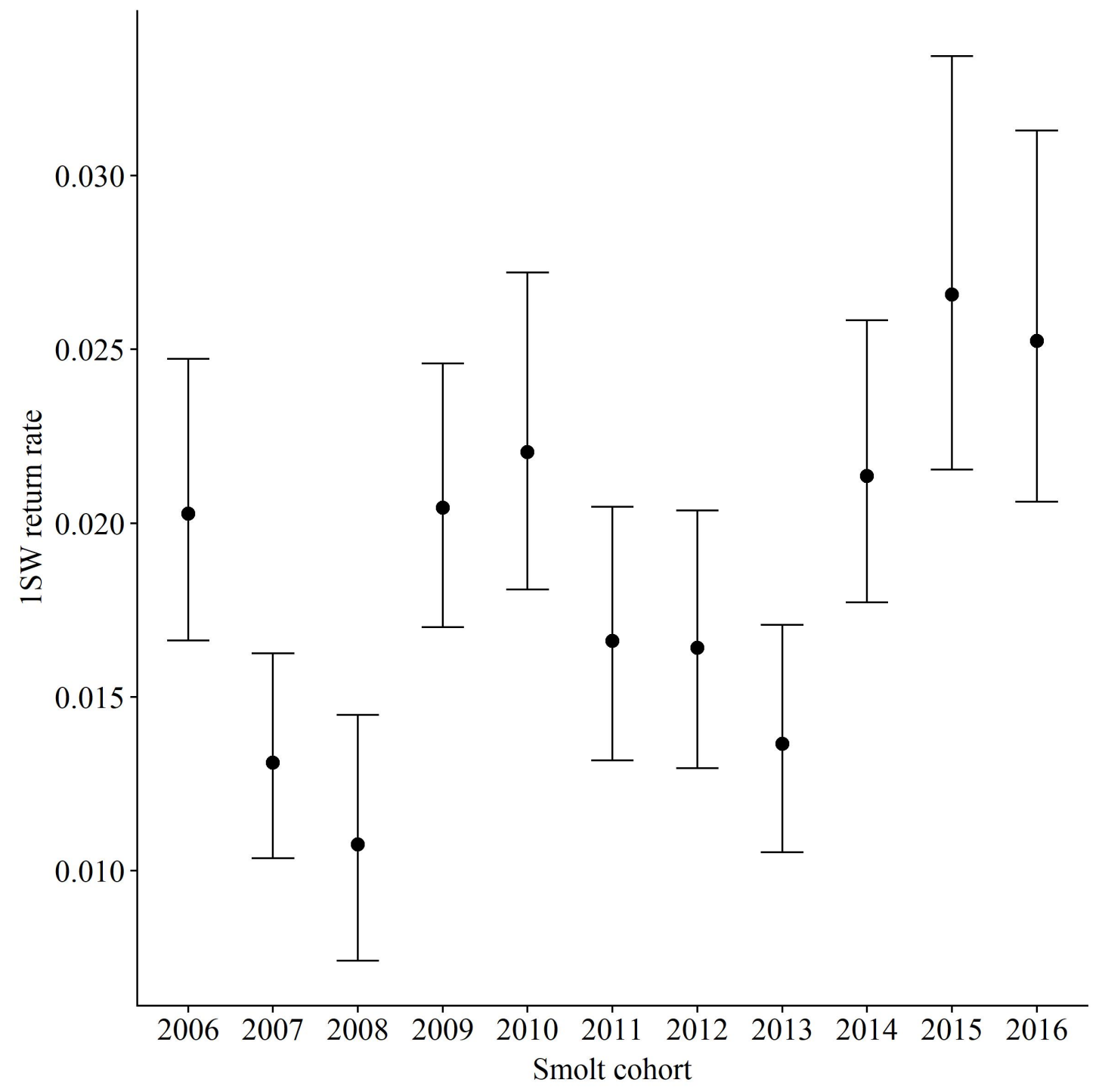

Figure 5 Estimated 1SW marine return rate for each smolt cohort for the "Length" model. Points are median estimates and error bars represent the 25 and 75\% Bayesian credibility interval (approximate standard errors).

\section{Discussion}

Using individual smolt data collected on the River Frome for an 11-year period and Bayesian model selection, we have shown credible evidence for an effect of Atlantic salmon smolt length on their marine return rate as 1SW. This effect was substantial within the normal range of River Frome smolt sizes (length quantiles: $2.5 \%=118 \mathrm{~mm}, 50 \%=140$, $97.5 \%=161$; Figure S5), increasing the probability of $1 \mathrm{SW}$ return rate from $<1 \%$ to $3.5 \%$ 
for a $12 \mathrm{~cm}$ to a $16 \mathrm{~cm}$ smolt, respectively. As few similar studies have had access to such individual data on smolt emigration and adult returns in conjunction with well-adapted statistical methods (Gregory et al., 2018), then their findings have been mixed; results from previous studies range from a positive effect of smolt size on marine return rate through to negative or no effects (Gregory et al., 2018). This is even when not accounting for studies that were not reported due to unexpected or lack of findings (Jennions and Moller, 2002). Aside from estimating the effect of smolt length on their subsequent marine return rate, our model estimated other parameters of interest. In particular, our model estimates the return rates of both 1 SW and MSW. MSW return rate was estimated as approximately half the estimate of mean 1SW marine return rate, and the 95\% Bayesian credible intervals of the estimate did not include zero. This suggests that there is a real and non-negligible mortality associated with this life-history strategy, and notably higher than 1SW mortality (Potter et al., 2003; Chaput, 2012). However, this finding must be considered together with how our model was parameterised to separate 1SW and MSW return rates. Our aim was to test the effect of length on 1 Sw return rate, and we attempted this by estimating the length effect on the 1SW return rate of all 1SW and MSW fish and then adding an estimated length-independent and temporally constant to the estimated 1SW return rate for MSW fish, representing an additional mortality effect for spending more time at sea. This formulation will result in estimated MSW return rates that mirror the between-individual and temporal variations of 1SW return rates. These strong assumptions were the result of a tradeoff between desired ecological realism and the need to simplify the model to ensure all included effects could be estimated from the relatively low available returning adult sample size, which we confirmed through our simulation study. With more data it would be worthwhile exploring whether these strong assumptions are realistic or whether betweenindividual variability and temporal variation in the additional mortailty effect, $\delta$, is warranted.

Aside from the aforementioned MSW return rate parameterization limitation, we should also remain cognisant that return rates might not be actual survival (or mortality) rates because of the confusion between the mortality and the maturation schedule (probability to mature as a 1SW fish or later). Separating out the between-individual and temporal 
variations in marine survival and in the maturation schedule is a hard task as variations in return rates result from the combination of the two processes. Specifically, a low MSW return rate might result from a low survival during the second year at sea or from a low proportion of fish maturing as MSW (Massiot-Granier et al., 2014; Olmos et al., 2019). With appropriate and sufficient data, an exciting research avenue would be to reparameterize the model to separate out the between-individual and temporal variations on their survival and maturation schedule. For example, with sufficient data, it could be possible to explore the effect of length on 1SW and MSW return rates separately, while treating differences in the year of return using either independent or shared (hierarchical) temporal variations, and then compare the length effect for each group. Assuming data on heritability of maturation are available and suitable (e.g., Barson et al., 2015), then models designed specifically to integrate demographic and genetic processes could be useful to better separate the effects of survival and maturation schedule (e.g., Piou and Prevost, 2012).

Our model also separates variability due to the biological and the observation process. Observation parameters are often not of general interest, sometimes being referred to as nuisance parameters. However, they can help managers better understand their system, the data it produces, and how it might be used to improve management information for that and other stocks (Bentley, 2015). For example, the probability of observing an individual and the probability that an individual transitions between the first and second adult detection device, approximately $3 \mathrm{~km}$ upstream in this system, were estimated at approximately 0.70 and 0.74 , respectively. These estimates were lower than expected, and our simulation study suggested that their results could be biased, particularly $\psi$ that was estimated high in all three scenarios. Therefore, rather than interpreting their estimates, we suggest that they be explored more carefully using simulation and observed data by: (1) considering the effect of covariates, including river conditions such as flow, on the probability of observing an individual (which might capture most of the variability between 1SW and MSW fish detection efficiencies, as those two age class migrate in different seasons); and (2) attempting to separate the effects of mortality and stopped migration on the probability that an individual transitions between the first and second adult detection devices. We suggest that any investigation uses both simulated and observed data to 
overcome the somewhat limited data available to explore the individual and combined effects of river condition and a limited sample of returning adults on the accuracy and precision of model parameter estimates: both estimates were also based on only six years of data and on relatively few individuals.

Although our model represents a robust approach to estimating the effect of smolt length on their subsequent marine return rate, there are many other factors that might explain a non-negligible amount of the overall or unexplained variation. For example, migration timing will affect both the length attained at migration and also the marine conditions that smolt encounter when they arrive at sea (Otero et al., 2014; Todd et al., 2012). A more direct measure of the initial marine conditions might be a measure of sea surface temperature (Friedland et al., 2009; Jensen et al., 2011) or food availability, as measured through phytoplankton blooms (Beaugrand and Reid, 2012). If there is any systematic change in smolt length through time, then the model ought to capture this to ensure it isn't absorbed into the estimated effects of annual deviations. Although our study is limited to smolt length as an explanatory variable of $1 \mathrm{SW}$ marine return rate, our model was developed to be extensible and general and it would be straightforward to admit alternative and additional explanatory variables such as those mentioned.

Other potential shortcomings of our approach might include that (1) the model is restricted to a single age smolt, an artefact of the low (generally $<3 \%$ but consistent: Figure S7) number of older smolts present in the data used for model development; (2) certain model parameters being considered as constant, whereas they might be better considered as fluctuating with time or a measurable covariate; (3) our findings are developed on data collected for a single river system; and (4) our model imposed a linear relationship between smolt length and their first year survival at sea. These are all legitimate concerns that warrant further investigation. For example, is any length effect independent of age, as was found for salmon smolts in the River Imsa, Norway (Jonsson et al., 2016)? And, is a strictly linear relationship between smolt length and their 1SW survival to be expected, given some support for a non-linear relationship (Jonsson et al., 2017)? However, all these factors - and more - were considered when developing our model, which led us to use the robust and flexible class of state-space models (Parent and Rivot, 2012). Indeed, our model 
was developed with the intention that it would be used to understand if the effect of smolt length on their survival was a more general finding (Gregory et al., 2018), as is suggested by a similar finding for robust data collected on the River Conon in Scotland (Armstrong et al., 2018).

Despite its necessary complexity, our model is limited to inferences about patterns in population changes, i.e., it is phenomenological. It is interesting to speculate about the sizespecific mechanisms that might give rise to our findings. One hypothesis might be that larger smolts are more able to escape gape-limited predators by merit of their stronger swimming ability or size. For example, Dieperink et al. (2001) found that smaller wild sea trout Salmo trutta smolts were predated by seabirds at a higher rate than larger smolts (67\% vs. $40 \%$ based on 18 and 15 emigrating sea trout smolts, respectively). Alternatively, smaller size smolts might take different migration routes or feed in different locations compared to their larger conspecifics. For example, Jutila et al. (2006) suggests that larger salmon smolts in the northern Baltic Sea remain in nearby feeding areas when food availability is high, whereas smaller smolts migrate further to different feeding grounds, potentially resulting in higher energetic costs. Relative to smaller smolts, larger smolts might be in better condition and will therefore grow better, as was shown for brown trout S. trutta in northern Norway (Jensen et al., 2018), and will have higher survival rates, as was shown for salmon smolts in Scotland Armstrong et al. (2018), perhaps due to higher resilience to inhospitable marine conditions (Malerba et al., 2018).

In conclusion, we present credible support for an effect of Atlantic salmon smolt length on their subsequent $1 \mathrm{SW}$ marine return rate. Our findings add support to the growing, yet still equivocal evidence that 'bigger is better' among salmon smolts (Gregory et al., 2018). Moreover, our model provides an extensible and flexible approach to exploring the generality of this pattern, across rivers and datasets. Our findings suggest that factors affecting salmon in their freshwater phase has a significant influence on their later life stages, including those at sea, and thus affects their fitness (Russell et al., 2012). Since it is easier to affect management actions in the freshwater relative to the marine environment, in-river conditions, such as habitat cover and food availability, could be managed to nurture larger and better condition salmon smolts (e.g., Grant et al., 2017), particularly on 
the River Frome where recent work has already revealed that salmon juveniles are getting smaller (Gregory et al., 2017).

\section{Acknowledgements}

Special thanks to all the people involved in collecting the data used in this study, including present and past members of the GWCT Fisheries Department, Cefas, the landowners, farming and fishery interests for facilitating access to the river, and all the many volunteers who have given up their time to help the imperilled salmon population of the River Frome. Some of the work was completed whilst A.T.I. was employed at the Centre for Ecology and Hydrology, Wallingford, U.K. and he is grateful to them for support during that period. The study was part-funded by the European Regional Development Fund through the Interreg Channel VA Programme, and the U.K. Government's Department for Environment, Food and Rural Affairs (Defra) under contracts SF0258, SF0272 \& SA001.

\section{References}

Armstrong, J. D, S. McKelvey, G. W. Smith, et al. (2018). “Effects of individual variation in length, condition and run-time on return rates of wild-reared Atlantic salmon Salmo salar smolts". In: Journal of Fish Biology 92.3, pp. 569-578. DOI: 10.1111/jfb.13548.

Baglinière, J. and G. Maisse (1985). "Precocious maturation and smoltification in wild Atlantic salmon in the Armorican Massif, France”. In: Aquaculture 45.1, pp. 249-263. ISSN: 0044-8486.

Baker, C. F, R. Kathryn, B. Dylan, et al. (2017). “Efficacy of 12-mm Half-Duplex Passive Integrated Transponder Tags in Monitoring Fish Movements through Stationary Antenna Systems". In: North American Journal of Fisheries Management 37.6, pp. 1289-1298. DOI: 10.1080/02755947.2017.1376011.

Barson, N. J, T. Aykanat, K. Hindar, et al. (2015). "Sex-dependent dominance at a single locus maintains variation in age at maturity in salmon". In: Nature 528.7582, pp. 405-408. ISSN: 0028-0836. DOI: 10.1038/nature16062. 
Beaugrand, G. and P. C. Reid (2012). "Relationships between North Atlantic salmon, plankton, and hydroclimatic change in the Northeast Atlantic". In: ICES Journal of Marine Science 69.9, pp. 1549-1562. DOI: 10.1093/icesjms/fss153.

Bentley, N. (2015). "Data and time poverty in fisheries estimation: potential approaches and solutions". In: ICES Journal of Marine Science: Journal du Conseil 72, pp. 186-193. DOI: 10.1093/icesjms/fsu023.

Brooks, S. P. and A. Gelman (1998). "General Methods for Monitoring Convergence of Iterative Simulations". In: Journal of Computational and Graphical Statistics 7.4, pp. 434455. DOI: $10.1080 / 10618600.1998 .10474787$.

Chaput, G. (2012). "Overview of the status of Atlantic salmon (Salmo salar) in the North Atlantic and trends in marine mortality". In: ICES Journal of Marine Science 69, pp. 15381548. DOI: 10.1093/icesjms/fss013.

Clutton-Brock, T. and B. C. Sheldon (2010). "Individuals and populations: the role of longterm, individual-based studies of animals in ecology and evolutionary biology". In: Trends in Ecology \& Evolution 25.10, pp. 562-573. DOI: 10.1016/j.tree.2010.08.002.

Cooch, E. and G. White (2001). Program Mark: A Gentle Introduction. Colorado State University. Available at http://www. phidot. org/software/mark/docs/book/.

Dempson, J., C. Mullins, C. Bourgeois, et al. (2003). "Perspectives on smolt production and marine survival of Newfoundland Atlantic salmon (Salmo salar L.) related to smolt size and run timing". In: Marine mortality of Atlantic salmon, Salmo salar L: methods and measures. Ed. by E. C. E. Potter, N. O. Maoileidigh and G. Chaput.

Dieperink, C, B. D. Bak, L. Pedersen, et al. (2002). "Predation on Atlantic salmon and sea trout during their first days as postsmolts". In: Journal of Fish Biology 61.3, pp. 848-852. ISSN: 1095-8649. DOI: 10.1111/j.1095-8649.2002.tb00917.x.

Dieperink, C, S. Pedersen and M. I. Pedersen (2001). "Estuarine predation on radiotagged wild and domesticated sea trout (Salmo trutta L.) smolts". In: Ecology of Freshwater Fish 10.3, pp. 177-183. ISSN: 1600-0633. DOI: 10.1034/j.1600-0633.2001.100307.x. 
Ewing, R. D. and G. S. Ewing (2002). "Bimodal length distributions of cultured chinook salmon and the relationship of length modes to adult survival". In: Aquaculture 209.1-4, pp. 139-155. DOI: 10.1016/S0044-8486(01)00755-4.

Friedland, K. D. (1998). “Ocean climate influences on critical Atlantic salmon (Salmo salar) life history events". In: Canadian Journal of Fisheries and Aquatic Sciences 55.S1, pp. 119130. ISSN: 0706-652X. DOI: 10.1139/d98-003.

Friedland, K. D, L. P. Hansen, D. A. Dunkley, et al. (2000). "Linkage between ocean climate, post-smolt growth, and survival of Atlantic salmon (Salmo salar L.) in the North Sea area". In: ICES Journal of Marine Science 57.2, pp. 419-429. DOI: 10.1006/jmsc.1999.0639.

Friedland, K. D, D. G. Reddin, J. R. McMenemy, et al. (2003). “Multidecadal trends in North American Atlantic salmon (Salmo salar) stocks and climate trends relevant to juvenile survival". In: Canadian Journal of Fisheries and Aquatic Sciences 60.5, pp. 563-583. DOI: 10.1139/f03-047.

Friedland, K, J. MacLean, L. Hansen, et al. (2009). “The recruitment of Atlantic salmon in Europe". In: ICES Journal of Marine Science 66.2, pp. 289-304. DOI:

10.1093/icesjms/fsn210.

Gimenez, O, E. Cam and J. Gaillard (2018). "Individual heterogeneity and capture-recapture models: what, why and how?" In: Oikos 127.5, pp. 664-686. DOI: 10.1111/oik.04532.

Gimenez, O, V. Rossi, R. Choquet, et al. (2007). "State-space modelling of data on marked individuals". In: Ecological Modelling 206.3-4, pp. 431-438. DOI:

10.1016/j.ecolmodel.2007.03.040.

Grant, J. W. A, L. K. Weir and S. Ãf. SteingrãfÂ-msson (2017). “Territory Size Decreases Minimally with Increasing Food Abundance in Stream Salmonids: Implications for Population Regulation". In: Journal of Animal Ecology 86.6, pp. 1308-1316. DOI: 10.1111/1365-2656.12737. 
Gregory, S. D, J. D. Armstrong and J. R. Britton (2018). "Is bigger really better? Towards improved models for testing how Atlantic salmon Salmo salar smolt size affects marine survival". In: Journal of Fish Biology 92.3, pp. 579-592. DOI: 10.1111/jfb.13550.

Gregory, S. D, M. Nevoux, W. D. Riley, et al. (2017). "Patterns on a parr: Drivers of long-term salmon parr length in U.K. and French rivers depend on geographical scale". In: Freshwater Biology 62.7, pp. 1117-1129. DOI: 10.1111/fwb.12929.

Henderson, M. A. and A. J. Cass (1991). "Effect of Smolt Size on Smolt-to-Adult Survival for Chilko Lake Sockeye Salmon (Oncorhynchus nerka)". In: Canadian Journal of Fisheries and Aquatic Sciences 48.6, pp. 988-994. DOI: 10.1139/f91-115.

Hogan, F. and K. D. Friedland (2010). "Retrospective growth analysis of Atlantic salmon Salmo salar and implications for abundance trends". In: Journal of Fish Biology 76.10, pp. 2502-2520. DOI: 10.1111/j.1095-8649.2010.02650.x.

Holtby, L. B, B. C. Andersen and R. K. Kadowaki (1990). "Importance of Smolt Size and Early Ocean Growth to Interannual Variability in Marine Survival of Coho Salmon (Oncorhynchus kisutch)". In: Canadian Journal of Fisheries and Aquatic Sciences 47.11, pp. 2181-2194. DOI: 10.1139/f90-243.

Ibbotson, A. T, W. D. Riley, W. R. Beaumont, et al. (2013). "The source of autumn and spring downstream migrating juvenile Atlantic salmon in a small lowland river". In: Ecology Freshwater Fish 22.1, pp. 73-81. ISSN: 1600-0633. DOI: 10.1111/eff.12003.

Jennions, M. D. and A. P. Moller (2002). "Publication bias in ecology and evolution: an empirical assessment using the â€ trim and fillâ€ $€^{\mathrm{TM}}$ method". In: Biological Reviews 77.2, pp. 211-222. DOI: $10.1017 / \mathrm{s} 1464793101005875$.

Jensen, A. J, B. Finstad and P. Fiske (2018). "Evidence for the linkage of survival of anadromous Arctic char and brown trout during winter to marine growth during the previous summer". In: Canadian Journal of Fisheries and Aquatic Sciences 75.5, pp. 663-672. DOI: $10.1139 /$ cjfas-2017-0077. 
Jensen, A. J, P. Fiske, L. P. Hansen, et al. (2011). "Synchrony in marine growth among Atlantic salmon (Salmo salar) populations". In: Canadian Journal of Fisheries and Aquatic Sciences 68.3, pp. 444-457. DOI: 10.1139/F10-156.

Jonsson, B, M. Jonsson and N. Jonsson (2016). “Optimal size at seaward migration in an anadromous salmonid". In: Marine Ecology Progress Series 559, pp. 193-200. DOI: 10.3354/meps11891.

Jonsson, B, M. Jonsson and N. Jonsson (2017). "Influences of migration phenology on survival are size dependent in juvenile Atlantic salmon (Salmo salar)". In: Canadian Journal of Zoology 95, pp. 581-587. ISSN: 0008-4301. DOI: 10.1139/cjz-2016-0136.

Jutila, E, E. Jokikokko and M. Julkunen (2006). "Long-term changes in the smolt size and age of Atlantic salmon, Salmo salar L, in a northern Baltic river related to parr density, growth opportunity and postsmolt survival". In: Ecology of Freshwater Fish 15.3, pp. 321-330. ISSN: 1600-0633. DOI: 10.1111/j.1600-0633.2006.00171.x.

Kéry, M. and M. Schaub (2012). Bayesian population analysis using WinBUGS: a hierarchical perspective. Academic Press.

Kéry, M. and B. R. Schmidt (2008). "Imperfect detection and its consequences for monitoring for conservation". In: Community Ecology 9.2, pp. 207-216. DOI: 10.1556/ComEc.9.2008.2.10.

Koenings, J. P, H. J. Geiger and J. J. Hasbrouck (1993). "Smolt-to-AduIt Survival Patterns of Sockeye Salmon (Oncorhynchus nerka): Effects of Smolt Length and Geographic Latitude when Entering the Sea". In: Canadian Journal of Fisheries and Aquatic Sciences 50.3, pp. 600611. DOI: $10.1139 /$ f93-069.

Limburg, K. E. and J. R. Waldman (2009). "Dramatic declines in North Atlantic diadromous fishes". In: BioScience 59.11, pp. 955-965. DOI: 10.1525/bio.2009.59.11.7.

Malerba, M. E, M. M. Palacios and D. J. Marshall (2018). "Do larger individuals cope with resource fluctuations better? An artificial selection approach". In: Proceedings of the Royal Society B 285.1884. DOI: 10.1098/rspb.2018.1347. 
Massiot-Granier, F, E. Prevost, G. Chaput, et al. (2014). "Embedding stock assessment within an integrated hierarchical Bayesian life cycle modelling framework: an application to Atlantic salmon in the Northeast Atlantic". In: ICES Journal of Marine Science: Journal du Conseil ??, p. in press. DOI: 10.1093/icesjms/fst240.

Mills, K. E, A. J. Pershing, T. F. Sheehan, et al. (2013). “Climate and ecosystem linkages explain widespread declines in North American Atlantic salmon populations". In: Global Change Biology 19.10, pp. 3046-3061. ISSN: 1365-2486. DOI: 10.1111/gcb.12298. Moore, A, D. Cotter, V. Quayle, et al. (2008). "The impact of a pesticide on the physiology and behaviour of hatchery-reared Atlantic salmon, Salmo salar, smolts during the transition from fresh water to the marine environment". In: Fisheries Management and Ecology 15.5Ãđâ,ᄀÂ国6, pp. 385-392. DOI: 10.1111/j.1365-2400.2008.00622.x.

Newton, M, J. Barry, J. A. Dodd, et al. (2016). “Does size matter? A test of size-specific mortality in Atlantic salmon Salmo salar smolts tagged with acoustic transmitters". In: Journal of Fish Biology 89.3, pp. 1641-1650. ISSN: 1095-8649. DOI: 10.1111/jfb.13066. Olmos, M, F. Massiot-Granier, E. PrÃfÂ@(Cvost, et al. (2019). “Evidence for spatial coherence in time trends of marine life history traits of Atlantic salmon in the North Atlantic". In: Fish and Fisheries 0.0. DOI: 10.1111/faf.12345.

Otero, J, J. H. L’Abe-Lund, T. Castro-Santos, et al. (2014). "Basin-scale phenology and effects of climate variability on global timing of initial seaward migration of Atlantic salmon (Salmo salar)". In: Global Change Biology 20.1, pp. 61-75. DOI: 10.1111/gcb.12363.

Parent, E. and E. Rivot (2012). Introduction to hierarchical Bayesian modeling for ecological data. CRC Press.

Parrish, D. L, R. J. Behnke, S. R. Gephard, et al. (1998). “Why aren't there more Atlantic salmon (Salmo salar)?" In: Canadian Journal of Fisheries and Aquatic Sciences 55.S1, pp. 281-287. DOI: 10.1139/d98-012.

Peyronnet, A, K. D. Friedland and N. Ãfâ€œ Maoileidigh (2008). "Different ocean and climate factors control the marine survival of wild and hatchery Atlantic salmon Salmo 
salar in the north-east Atlantic Ocean". In: Journal of Fish Biology 73.4, pp. 945-962. ISSN: 1095-8649. DOI: 10.1111/j.1095-8649.2008.01984.x.

Peyronnet, A, K. D. Friedland, N. A. Maoileidigh, et al. (2007). "Links between patterns of marine growth and survival of Atlantic salmon Salmo salar, L." In: Journal of Fish Biology 71.3, pp. 684-700. ISSN: 1095-8649. DOI: 10.1111/j.1095-8649.2007.01538.x.

Piou, C. and E. Prevost (2012). "A demo-genetic individual-based model for Atlantic salmon populations: Model structure, parameterization and sensitivity". In: Ecological Modelling 231.0, pp. 37-52. ISSN: 0304-3800. DOI: 10.1016/j.ecolmodel.2012.01.025.

JAGS: A program for analysis of Bayesian graphical models using Gibbs sampling (2003). JAGS: A program for analysis of Bayesian graphical models using Gibbs sampling. Vol. 124. 125.10. Proceedings of the 3rd international workshop on distributed statistical computing.

Potter, E. C. E., L. P. Hansen, G. Gudbergsson, et al., ed. (1998). A method for estimating preliminary conservation limits for salmon stocks in the NASCO-NEAC area. CM 1998/T: 17. pp. 11.

Potter, E. C. E., N. O. Maoileidigh and G. Chaput, ed. (2003). Marine mortality of Atlantic salmon, Salmo salar L: methods and measures.

Ricker, W. E. (1976). "Review of the Rate of Growth and Mortality of Pacific Salmon in Salt Water, and Noncatch Mortality Caused by Fishing". In: Journal of the Fisheries Research Board of Canada 33.7, pp. 1483-1524. DOI: 10.1139/f76-191.

Riley, W. D, A. T. Ibbotson, W. R. C. Beaumont, et al. (2011). "Predation of the juvenile stages of diadromous fish by sea bass (Dicentrarchus labrax) in the tidal reaches of an English chalk stream". In: Aquatic Conservation-marine and Freshwater Ecosystems 21.3, pp. 307312. DOI: $10.1002 /$ aqc.1184.

Riley, W. D, A. T. Ibbotson, S. D. Gregory, et al. (2018). “Under what circumstances does the capture and tagging of wild Atlantic salmon Salmo salar smolts affect probability of return as adults?" In: Journal of Fish Biology 93, pp. 477-489. DOI: 10.1111/jfb.13655. 
Russell, I, M. Aprahamian, J. Barry, et al. (2012). “The influence of the freshwater environment and the biological characteristics of Atlantic salmon smolts on their subsequent marine survival". In: ICES Journal of Marine Science 69, pp. 1563-1573. ISSN: 1054-3139. DOI: 10.1093/icesjms/fsr208.

Sogard, S. M. (1997). "Size-selective mortality in the juvenile stage of teleost fishes: a review". In: Bulletin of Marine Science 60.3, pp. 1129-1157.

Todd, C. D, K. D. Friedland, J. C. MacLean, et al. (2012). “Phenological and phenotypic changes in Atlantic salmon populations in response to a changing climate". In: ICES Journal of Marine Science 69.9, pp. 1686-1698. DOI: 10.1093/icesjms/fss151.

Vehtari, A, A. Gelman and J. Gabry (2017). "Practical Bayesian model evaluation using leaveone-out cross-validation and WAIC". In: Statistics and Computing 27.5, pp. 1413-1432.

Withler, R. E, W. C. Clarke, B. E. Riddell, et al. (1987). “Genetic variation in freshwater survival and growth of chinook salmon (Oncorhynchus tshawytscha)". In: Aquaculture 64.2, pp. 85-96. DOI: 10.1016/0044-8486(87)90344-9. 


\section{Supplementary material}
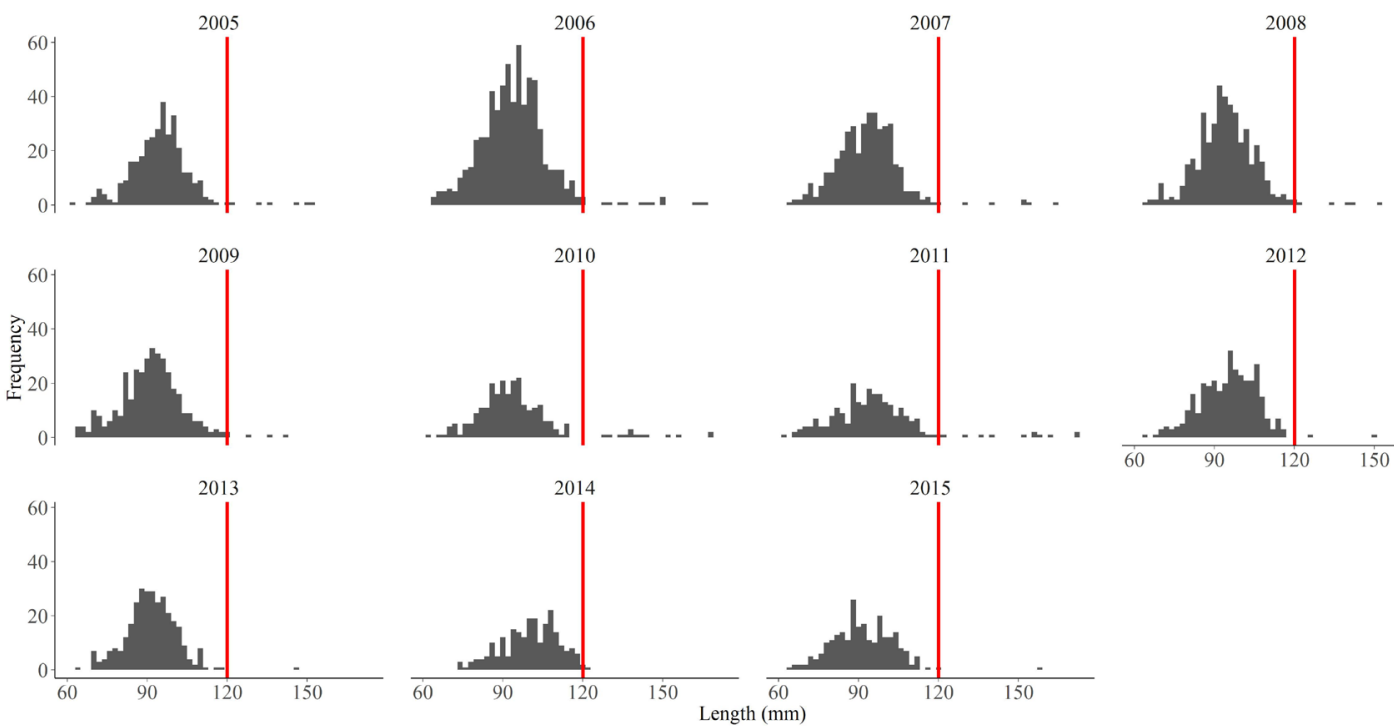

Figure S1 Year-specific length-frequency histograms showing that the large majority of salmon parr tagged in autumn were young-of-the-year, i.e., age 0+. Older smolts were removed from the River Frome data analysis, and tended to be those individuals $\geq 120 \mathrm{~mm}$ in the autumn that they were tagged.
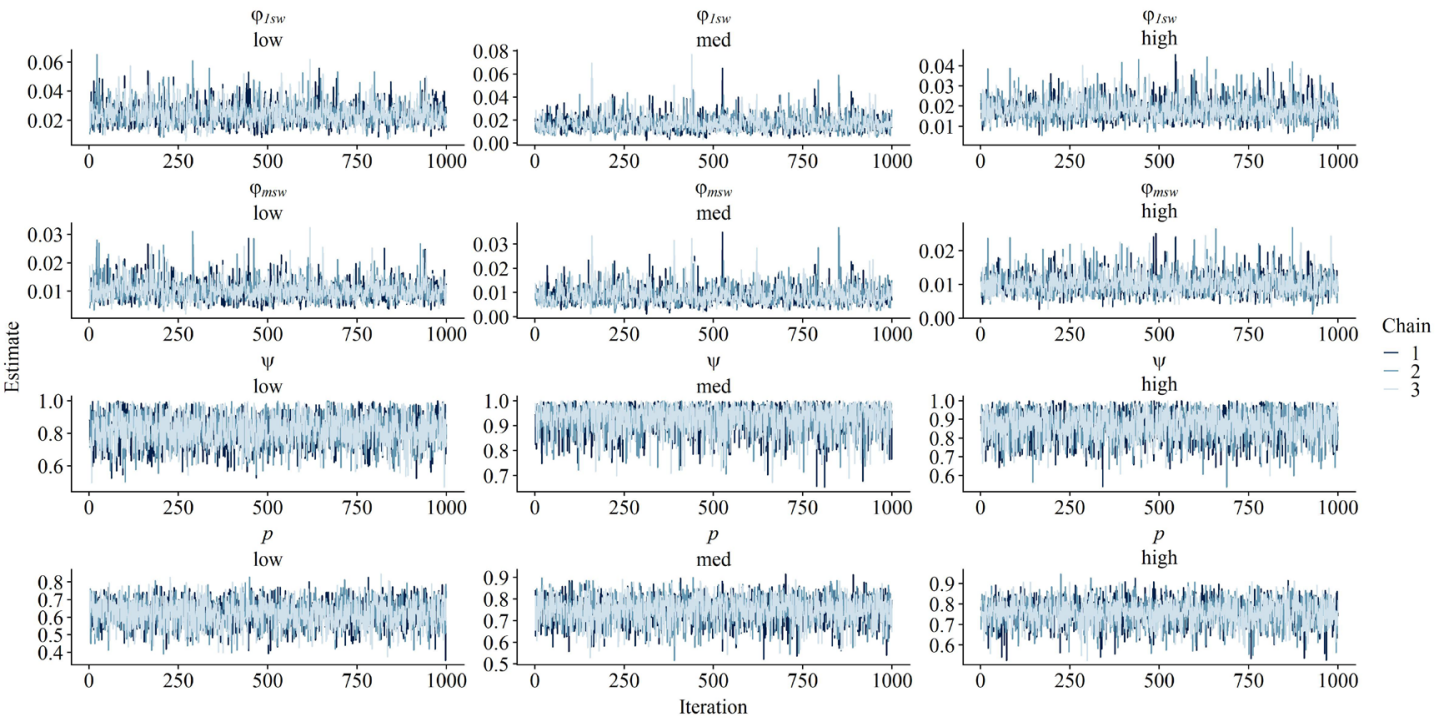

Figure S2 Trace plots of monitored parameters for model fit to simulated data. 


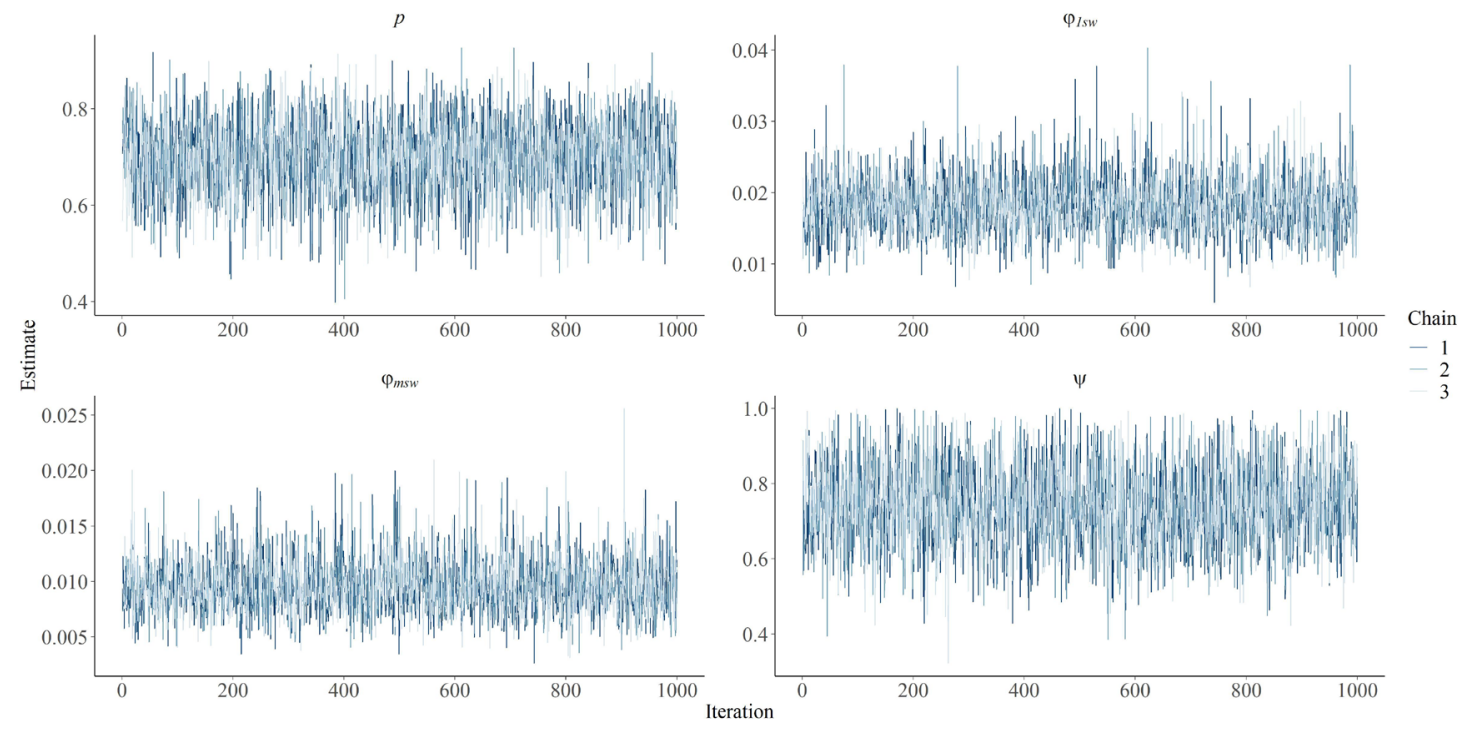

Figure S3 Trace plots of monitored parameters for model fit to River Frome data. 


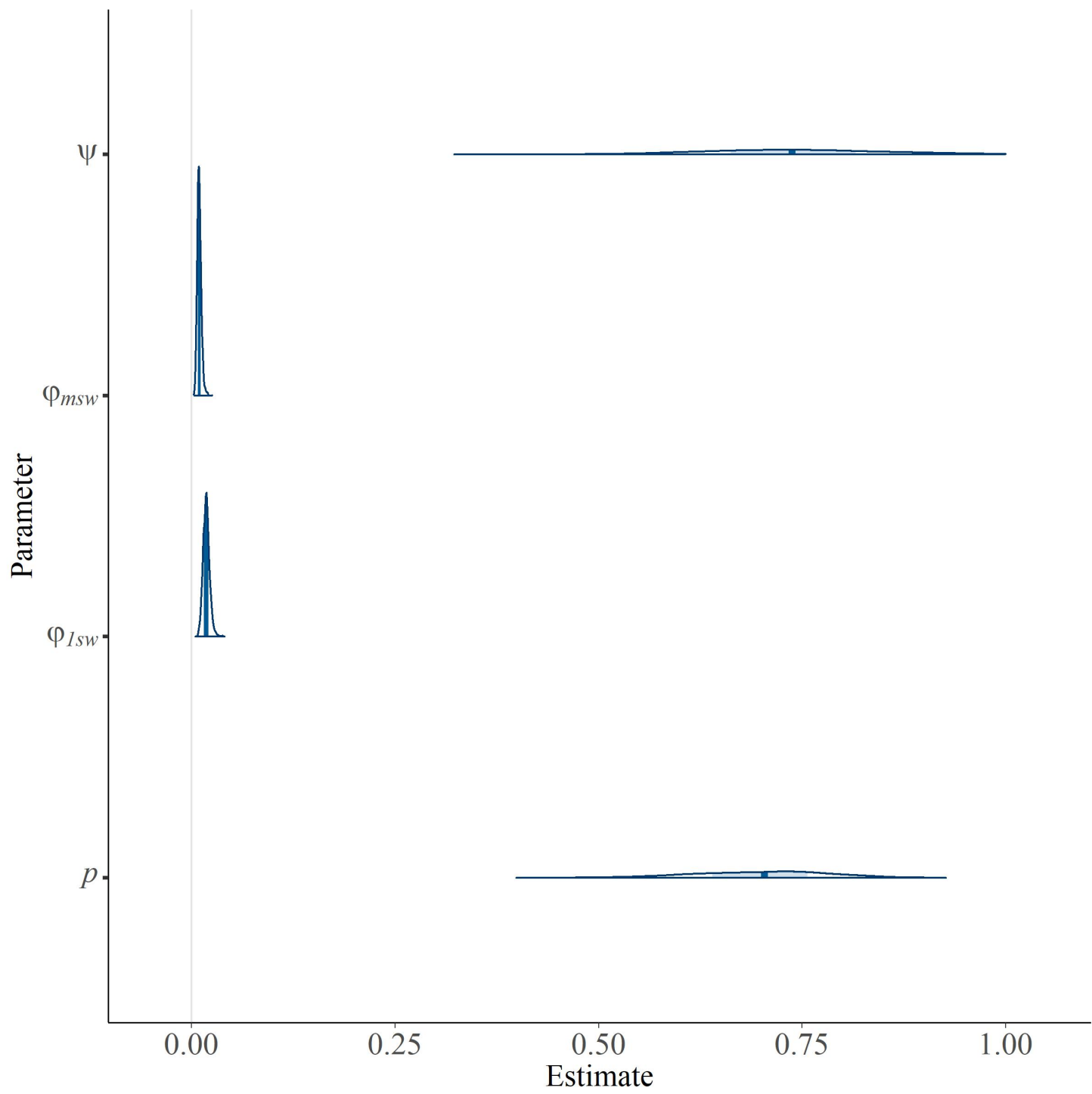

Figure S4 Posterior plots of monitored parameters for model fit to River Frome data. 

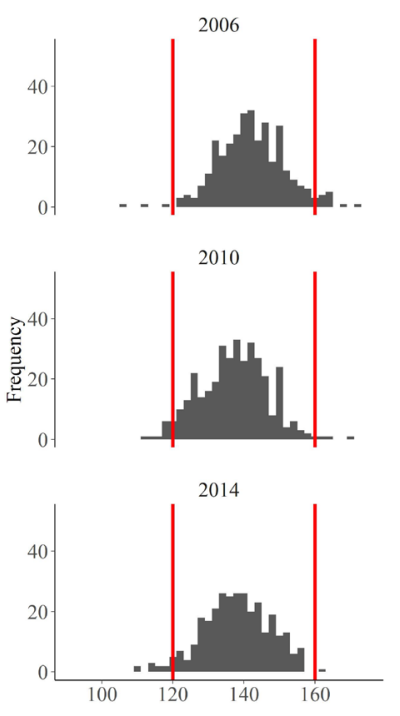
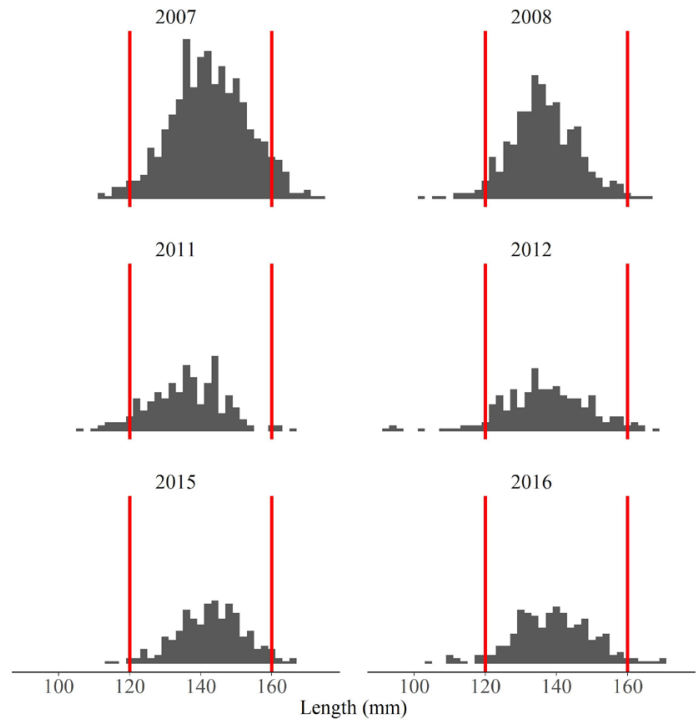

2012

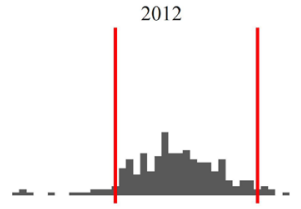

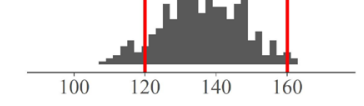

Figure S5 Year-specific length-frequency histograms showing the distribution of salmon smolt lengths and the locations of 120 and $160 \mathrm{~mm}$ smolts in the year-specific distributions. 


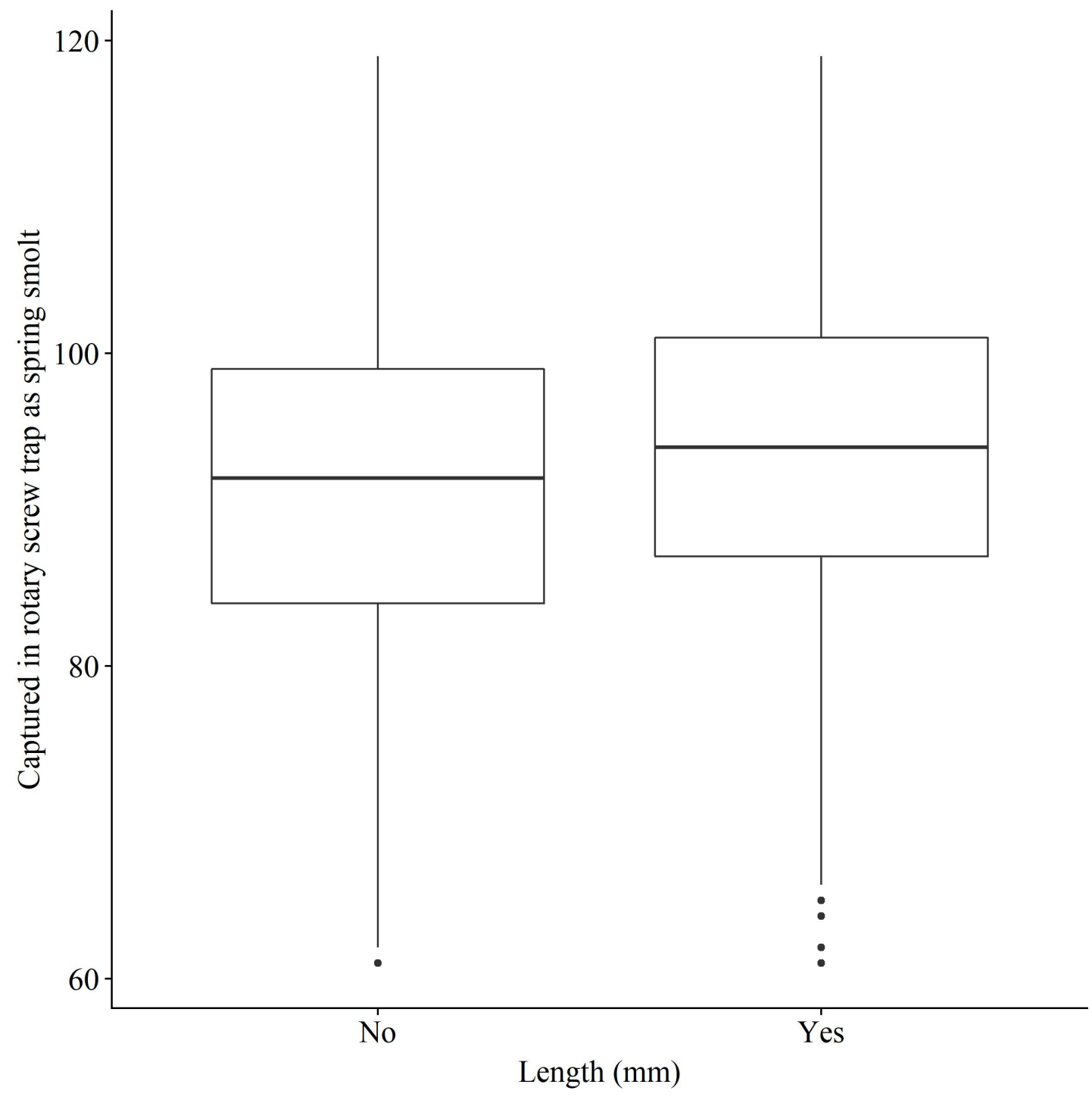

Figure S6 Boxplot showing the lengths of salmon parr PIT-tagged in the autumn grouped by whether they were trapped in the RST as smolts in spring. 


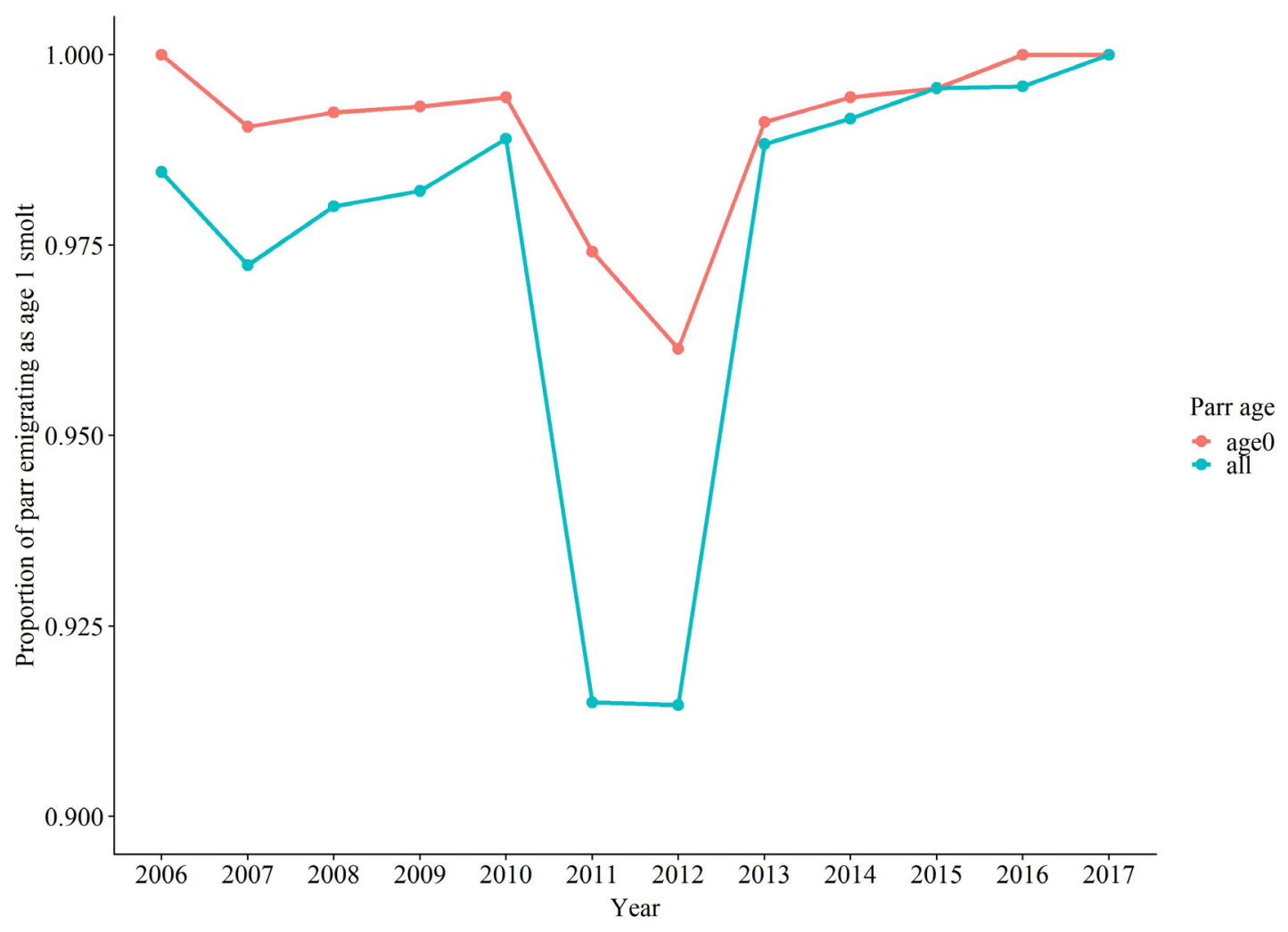

Figure $\mathbf{S 7}$ A line plot showing the proportion of different age parr emigrating from the River Frome as age 1 smolts. Note the y-axis origin is 0.9 . 